\title{
PARÁMETROS REPRODUCTIVOS DEL GANADO VACUNO EN LA CUENCA LECHERA DE LIMA
}

\author{
Cattle Reproductive Parameters in the Lima Dairy Region
}

Dante Ortiz A. ${ }^{1}$, José Camacho S. ${ }^{1,2}$ y Luisa Echevarría C.,

\section{Resumen}

Se determinó la edad al primer servicio (EPS), edad al primer parto (EPP), intervalo parto - primer servicio (IPPS), intervalo parto - concepción (IPC), intervalo entre partos (IEP), número de servicios por concepción (NSC), tasa de concepción al primer servicio (TCPS) y tasa de concepción global (TCG), en base a registros históricos de 559 vacas Holstein de 4 establos de lechería intensiva de la cuenca lechera de Lima. Se analizó las variables establo, época de parto (verano: diciembre a marzo; invierno: abril a agosto; y primavera: setiembre a noviembre) y número de partos (primíparas; multíparas). El EPS fue de 17.5 \pm 0.1 meses $(n=559)$, EPP de 27.2 \pm 0.2 meses, $(n=455)$, IPPS de 109.2 \pm 1.5 días $(\mathrm{n}=1233)$, IPC de $181.1 \pm 3.4$ días $(\mathrm{n}=1035)$, IEP de 15.2 \pm 0.1 meses $(\mathrm{n}=775)$, NSC de 2.41 , TCPS de $46.1 \%$ (66.9 y $36.5 \%$ en vaquillas y vacas, respectivamente) y TCG de $41.5 \%$. El IPPS de vacas con parto en invierno fue estadísticamente más corto que en vacas paridas en primavera y verano (105.0 vs. 112.7 y 113.8 días, respectivamente). Asimismo, las multíparas tuvieron un mejor comportamiento reproductivo que las primíparas.

Palabras clave: parámetros reproductivos, vacas, Lima

\section{AbStract}

The age at first service (EPS), age at first calving (EPP), calving - first service interval (IPPS), calving - conception interval (IPC), inter-calving interval (IEP), number of services per conception (NSC), conception rate at first service (TCPS) and overall conception rate (TCG) were determined from historical data of 559 dairy cows from 4 intensive milk dairy farms in the Lima region. Variables under analysis were farm, calving season (summer: December-March; winter: April-August; spring: September-November) and parity (primmiparous; multiparous). EPS was $17.5 \pm 0.1$ months $(\mathrm{n}=559)$, EPP was $27.2 \pm 0.2$ months $(\mathrm{n}=455)$, IPPS was $109.2 \pm 1.5$ days $(\mathrm{n}=1233)$, IPC was $181.1 \pm 3.4$ days $(\mathrm{n}=1035)$, IEP was $15.2 \pm 0.1$ months $(n=775)$, NSC was 2.41 , TCPS was $46.1 \%(66.9$ and $36.5 \%$ en heifers and cows, respectively) and TCG was $41.5 \%$. IPPS of cows that calved in winter

1 Laboratorio de Zootecnia y Producción Agropecuaria, ${ }^{3}$ Laboratorio de Reproducción Animal, Facultad de Medicina Veterinaria, Universidad Nacional Mayor de San Marcos, Lima

2 E-mail:joscams@hotmail.com

4 Dirección Actual: Facultad de Veterinaria y Zootecnia, Universidad Peruana Cayetano Heredia.

E-mail:luisa_ech@hotmail.com 
was statistically shorter that for cows calving in spring and summer (105.0 vs. 112.7 and 113.8 days, respectively). Likewise, multiparous cows showed better reproductive performance than primmiparous cows.

Key words: reproductive parameters, cows, Lima

\section{INTRODUCCIÓN}

Muchos de los estudios realizados sobre la situación productiva y reproductiva del ganado lechero en las principales cuencas del Perú recomiendan realizar trabajos complementarios que determinen los actuales parámetros productivos y reproductivos en esas zonas (Gamarra, 2001).

Actualmente, la disponibilidad de programas informáticos permite un adecuado manejo de datos que facilita la obtención y análisis de información histórica, de modo que el profesional de campo y el ganadero puedan conocer la situación actual del hato, identificar los problemas técnicos existentes y aplicar los correctivos necesarios (García, 2004). Por otro lado, es conocida la influencia del medio ambiente sobre el comportamiento reproductivo animal, de allí que si la información productiva se encuentra debidamente registrada y analizada, se pueden proponer estrategias de manejo que permitan contrarrestar sus efectos perjudiciales, mejorando la productividad de los rebaños lecheros.

El presente estudio tuvo como objetivo determinar los parámetros reproductivos del ganado bovino en la cuenca lechera de Lima, y su relación con factores medioambientales y de manejo.

\section{Materiales y Métodos}

El trabajo se realizó en el valle de Lima, que se caracteriza por presentar temperaturas de 12 a $16{ }^{\circ} \mathrm{C}$ en invierno y 25 a $30^{\circ} \mathrm{C}$ en verano, con una humedad relativa entre $85 \mathrm{y}$
$90 \%$ y una precipitación pluvial anual de 26.6 a $29.2 \mathrm{~mm}$.

Se recolectó información de tarjetas individuales de 559 animales de la raza Holstein en cuatro establos de crianza intensiva, con similares características de manejo, y con alimentación basada en concentrados y forraje cortado. En estos establecimientos, la detección del celo se hacía visualmente durante el trabajo diario, y se practicaba la inseminación artificial con semen congelado. El ordeño se realizaba dos veces al día. Todos los establos recibían visitas frecuentes de médicos veterinarios quienes se encargan del aspecto sanitario. La información se recopiló desde el año 1994 hasta el año 2002 y se vació en el programa de cómputo LIMA (Livestock Information Management Application) (García, 2002).

La información de los animales se estratificó en base a la estación de parto (verano: diciembre a marzo; invierno: abril a agosto; y primavera: setiembre a noviembre) y número de partos (primíparas; multíparas).

Se determinó los siguientes parámetros reproductivos: edad al primer servicio (EPS), edad al primer parto (EPP), intervalo parto primer servicio (IPPS), intervalo parto - concepción (IPC), intervalo entre partos (IEP), número de servicios por concepción (NSC), tasa de concepción al primer servicio (TCPS) y tasa de concepción global (TCG). Los datos fueron analizados con el Programa SYSTAT determinándose los valores promedios y la varianza para cada parámetro. Se consideró como variables independientes al establo, estación de parto y número de partos, en tanto que los parámetros reproductivos se consideraron como variables dependientes. 


\section{Resultados}

Los promedios de EPS, EPP, IPPS, IPC e IPP por establo se muestran en el Cuadro 1. El IPPS e IPC fue significativamente menor $(p<0.05)$ en animales que parieron en el invierno en relación con los que parieron en primavera y verano (Cuadro 2).

El IPPS, IPC e IEP fue significativamente menor $(p<0.05)$ en vacas multíparas que en primípiras (Cuadro 3). Asimismo, se encontró diferencia estadística entre establos para NSC, TCPS y TCG, siendo los promedios globales de $2.41,46.1$ y $41.5 \%$, respectivamente (Cuadro 4). En general, el establo 1 tuvo el mejor comportamiento reproductivo y el establo 4 el más deficiente.

\section{Discusión}

Los vaquillas reciben su primer servicio a una edad avanzada y el primer parto recién está ocurriendo a los 27 meses, lo cual puede ser un indicio que las hembras no alcanzan el peso y tamaño adecuados a una edad apropiada para el servicio. La subnutrición inhibe el desarrollo del sistema reproductivo endocrino, especialmente la secreción pulsátil de LH (Westwood et al., 2002). Asimismo, el efecto del estrés de calor, que se presenta durante el verano en la zona de Lima afecta seriamente la fertilidad y la expresión del celo (Arana et al., 2006).

El IPPS es influenciado por la condición corporal (CC), el balance energético negativo (BEN), la estación del parto y el volumen de producción láctea (Inostroza y Sepúlveda, 1999; Echevarría et al., 2002). En casos de IPPS relativamente largos como el del presente estudio, extensos periodos de anestro postparto, problemas de expresión de signos de celo, fallas en la detección de celos, y deficiencia en el manejo de los registros pueden estar ocurriendo (Silva et al., 1992). Sepúlveda (2001) indica como una meta plausible que el
$85 \%$ de las vacas deben ser observadas en celo dentro de los 60 días del parto, de lo contrario cabe pensar en ausencia de actividad cíclica ovárica. El reinicio de esta actividad está regulada por el eje hipotálamohipófisis-gónada, en base a un adecuado balance endocrino y al reestablecimiento de la funcionalidad uterina tras la completa involución del tracto reproductivo (Inostroza y Sepúlveda, 1999). En condiciones fisiológicas normales y con el adecuado estatus alimenticio, la primera ovulación postparto, usualmente sin signos de celo, debe ocurrir dentro de las primeras tres semanas, pero la segunda ovulación, tres semanas más tarde, se debe presentar acompañada de signos de celo (Stevenson et al., 1983).

Se estima que entre el 45 a $80 \%$ de casos de infertilidad tienen como causa principal el factor nutricional (Loeffer et al., 1999). La evaluación de la CC es una forma simple de medir el estado nutricional del animal. Vacas con pobre $\mathrm{CC}$ al parto y que además pierden peso luego del parto o que son altas productoras toman más tiempo en reiniciar su actividad cíclica; sin embargo, no es solo la CC al parto, sino la magnitud de su pérdida es lo que afecta la función reproductiva (Butler y Smith, 1989). Deficiencias energéticas en la alimentación se traducen en un marcado BEN que afectará la fertilidad del animal (Sepúlveda, 2001). El BEN ocasiona la depresión de insulina y de la liberación de GnRH, que afecta en consecuencia la liberación de FSH y la frecuencia pulsátil de LH, provocando una disminución de la función ovárica que origina retraso en la ovulación y por consiguiente el incremento del periodo de anestro (Butler y Smith, 1989; Sepúlveda, 2001).

La mejor eficiencia reproductiva se encontró en animales con partos en los meses más fríos del año. La raza Holstein ha sido desarrollada en los climas relativamente fríos de Europa, por lo tanto, su mejor comportamiento lo alcanzan cuando están dentro de su temperatura termoneutral que es de 13 a 
Cuadro 1. Edad al primer servicio (EPS), edad al primer parto (EPP), intervalo parto primer servicio (IPPS), intervalo parto - concepción (IPC) e intervalo entre partos (IEP) de vacas lecheras en cuatro establos de la cuenca lechera de Lima

\begin{tabular}{cccccc}
\hline Establo & $\begin{array}{c}\text { EPS } \\
\text { Prom } \pm \text { e.e. } \\
(\text { meses })\end{array}$ & $\begin{array}{c}\text { EPP } \\
\text { Prom } \pm \text { e.e. } \\
(\text { meses })\end{array}$ & $\begin{array}{c}\text { IPPS } \\
\text { Prom } \pm \text { e.e. } \\
(\text { días })\end{array}$ & $\begin{array}{c}\text { IPC } \\
\text { Prom } \pm \text { e.e. } \\
(\text { días })\end{array}$ & $\begin{array}{c}\text { IEP } \\
\text { Prom } \pm \text { e.e. } \\
(\text { meses })\end{array}$ \\
\hline 1 & $\begin{array}{c}19.7 \pm 0.3^{\mathrm{a}} \\
(\mathrm{n}=76)\end{array}$ & $\begin{array}{c}29.9 \pm 0.4^{\mathrm{a}} \\
(\mathrm{n}=66)\end{array}$ & $\begin{array}{c}104.2 \pm 4.2^{\mathrm{a}} \\
(\mathrm{n}=152)\end{array}$ & $\begin{array}{c}172.6 \pm 9.7^{\mathrm{a}} \\
(\mathrm{n}=124)\end{array}$ & $\begin{array}{c}15.1 \pm 0.4^{\mathrm{a}} \\
(\mathrm{n}=85)\end{array}$ \\
2 & $\begin{array}{c}17.7 \pm 0.3^{\mathrm{b}} \\
(\mathrm{n}=69)\end{array}$ & $\begin{array}{c}28.5 \pm 0.5^{\mathrm{a}} \\
(\mathrm{n}=42)\end{array}$ & $\begin{array}{c}120.6 \pm 4.7^{\mathrm{b}} \\
(\mathrm{n}=120)\end{array}$ & $\begin{array}{c}197.9 \pm 10.2^{\mathrm{b}} \\
(\mathrm{n}=112)\end{array}$ & $\begin{array}{c}15.7 \pm 0.4^{\mathrm{a}} \\
(\mathrm{n}=80)\end{array}$ \\
3 & $\begin{array}{c}17.0 \pm 0.2^{\mathrm{b}} \\
(\mathrm{n}=214)\end{array}$ & $\begin{array}{c}26.6 \pm 0.2^{\mathrm{b}} \\
(\mathrm{n}=161)\end{array}$ & $\begin{array}{c}95.4 \pm 2.3^{\mathrm{a}} \\
(\mathrm{n}=497)\end{array}$ & $\begin{array}{c}156.7 \pm 5.2^{\mathrm{a}} \\
(\mathrm{n}=436)\end{array}$ & $\begin{array}{c}\left.14.4 \pm 0.2^{\mathrm{b}}\right) \\
(\mathrm{n}=330)\end{array}$ \\
4 & $\begin{array}{c}16.9 \pm 0.2^{\mathrm{b}} \\
(\mathrm{n}=200)\end{array}$ & $\begin{array}{c}26.5 \pm 0.2^{\mathrm{b}} \\
(\mathrm{n}=186)\end{array}$ & $\begin{array}{c}\left.122.5 \pm 2.4^{\mathrm{b}}\right) \\
(\mathrm{n}=464)\end{array}$ & $\begin{array}{c}208.2 \pm 5.7^{\mathrm{b}} \\
(\mathrm{n}=363)\end{array}$ & $\begin{array}{c}\left.16.1 \pm 0.2^{\mathrm{a}}\right) \\
(\mathrm{n}=280)\end{array}$ \\
\hline Prom. & $\begin{array}{c}17.5 \pm 0.1 \\
(\mathrm{n}=559)\end{array}$ & $\begin{array}{c}27.2 \pm 0.2 \\
(\mathrm{n}=455)\end{array}$ & $\begin{array}{c}109.2 \pm 1.5 \\
(\mathrm{n}=1233)\end{array}$ & $\begin{array}{c}181.1 \pm 3.4 \\
(\mathrm{n}=1035)\end{array}$ & $\begin{array}{c}15.2 \pm 0.1 \\
(\mathrm{n}=775)\end{array}$ \\
\hline
\end{tabular}

${ }^{a, b}$ Superíndices diferentes dentro de columnas indican diferencia estadística $(p<0.05)$

Cuadro 2. Intervalo parto - primer servicio (IPPS) e intervalo parto - concepción (IPC) de vacas Holstein de acuerdo a la estación de parto en cuatro establos de la cuenca lechera de Lima

\begin{tabular}{lcc}
\hline Estación de Parto & $\begin{array}{c}\text { IPPS } \\
\text { Prom. } \pm \text { e.e. } \\
\text { (días })\end{array}$ & $\begin{array}{c}\text { IPC } \\
\text { Prom } \pm \text { e.e. } \\
(\text { días })\end{array}$ \\
\hline Verano & $\begin{array}{c}112.7 \pm 2.9^{\mathrm{a}} \\
(\mathrm{n}=354)\end{array}$ & $\begin{array}{c}184.5 \pm 5.6^{\mathrm{a}} \\
(\mathrm{n}=318)\end{array}$ \\
Invierno & $\begin{array}{c}105.0 \pm 2.0^{\mathrm{b}} \\
(\mathrm{n}=606)\end{array}$ & $\begin{array}{c}176.7 \pm 5.2^{\mathrm{b}} \\
(\mathrm{n}=501)\end{array}$ \\
Primavera & $\begin{array}{c}113.8 \pm 3.7^{\mathrm{a}} \\
(\mathrm{n}=273)\end{array}$ & $\begin{array}{c}186.5 \pm 7.5^{\mathrm{a}} \\
(\mathrm{n}=216)\end{array}$ \\
\hline Promedio & $\begin{array}{c}109.2 \pm 1.5 \\
(\mathrm{n}=1233)\end{array}$ & $\begin{array}{c}181.1 \pm 3.4 \\
(\mathrm{n}=1035)\end{array}$ \\
\hline
\end{tabular}

${ }^{a, b}$ Superíndices diferentes dentro de columnas indican diferencia estadística $(p<0.05)$

$18^{\circ} \mathrm{C}$; y esto coincide con el invierno limeño. En contraparte, durante los meses calurosos del año no muestran fácilmente signos de celo
(Arana et al., 2006) y cuando lo hacen, la duración del celo es más corta (Stevenson et al., 1983). Se sabe también que a partir de 
Cuadro 3. Intervalo parto - primer servicio (IPPS) e intervalo parto - concepción (IPC) e intervalo entre partos (IEP) de vacas lecheras de acuerdo al número de partos (primíparas y multíparas) en cuatro establos de la cuenca lechera de Lima

\begin{tabular}{cccc}
\hline N. ${ }^{\circ}$ de Partos & $\begin{array}{c}\text { IPPS } \\
\text { Prom. } \pm \text { e.e. }\end{array}$ & $\begin{array}{c}\text { IPC } \\
\text { Prom. } \pm \text { e.e. } \\
\text { (días) }\end{array}$ & $\begin{array}{c}\text { IEP } \\
\text { Prom. } \pm \text { e.e. } \\
(\text { meses })\end{array}$ \\
\hline Primíparas & $\begin{array}{c}113.2 \pm 2.6^{\mathrm{a}} \\
(\mathrm{n}=461)\end{array}$ & $\begin{array}{c}172.0 \pm 4.5^{\mathrm{a}} \\
(\mathrm{n}=397)\end{array}$ & $\begin{array}{c}15.6 \pm 0.2^{\mathrm{a}} \\
(\mathrm{n}=329)\end{array}$ \\
Multíparas & $\begin{array}{c}108.3 \pm 2.0^{\mathrm{b}} \\
(\mathrm{n}=772)\end{array}$ & $\begin{array}{c}156.9 \pm 3.3^{\mathrm{b}} \\
(\mathrm{n}=638)\end{array}$ & $\begin{array}{c}15.2 \pm 0.2^{\mathrm{b}} \\
(\mathrm{n}=446)\end{array}$ \\
\hline Promedio & $\begin{array}{c}109.2 \pm 1.5 \\
(\mathrm{n}=1233)\end{array}$ & $\begin{array}{c}181.1 \pm 3.4 \\
(\mathrm{n}=1035)\end{array}$ & $\begin{array}{c}15.2 \pm 0.1 \\
(\mathrm{n}=775)\end{array}$ \\
\hline
\end{tabular}

${ }^{a, b}$ Superíndices diferentes dentro de columnas indican diferencia estadística $(p<0.05)$

Cuadro 4. Número de servicios por concepción (NSC), tasa de concepción al primer servicio (TCPS) y tasa de concepción global (TCG) de vacas lecheras en cuatro establos de la cuenca lechera de Lima

\begin{tabular}{cccc}
\hline Establo & $\begin{array}{c}\text { NSC } \\
\left(\mathrm{N}^{\mathrm{o}}\right)\end{array}$ & $\begin{array}{c}\text { TCPS } \\
(\%)\end{array}$ & $\begin{array}{c}\text { TCG } \\
(\%)\end{array}$ \\
\hline 1 & $2.14^{\mathrm{a}}$ & $55.4^{\mathrm{a}}$ & $46.8^{\mathrm{a}}$ \\
2 & $2.23^{\mathrm{a}}$ & $46.1^{\mathrm{b}}$ & $44.8^{\mathrm{a}}$ \\
3 & $2.20^{\mathrm{a}}$ & $47.9^{\mathrm{b}}$ & $45.4^{\mathrm{a}}$ \\
4 & $2.79^{\mathrm{b}}$ & $40.9^{\mathrm{c}}$ & $35.8^{\mathrm{b}}$ \\
\hline Promedio & 2.41 & 46.1 & 41.5 \\
\hline
\end{tabular}

${ }^{a, b}$ Superíndices diferentes dentro de columnas indican diferencia estadística $(p<0.05)$

$25{ }^{\circ} \mathrm{C}$, como sucede en el verano de la costa peruana, los animales tienen estrés de calor y comienzan a activar mecanismos de compensación (Salazar, 1992; Arana et al., 2006).

Las diferencias encontradas entre primíparas y multíparas eran esperadas. To- das las vacas pierden condición corporal luego del parto y sufren diferentes niveles de BEN, pero las más jóvenes no solo se enfrentan al estrés del parto y el desgaste normal del inicio de la lactación, sino que además están en crecimiento y, por lo tanto, demandan mayores necesidades energéticas. 
Por ello, vacas primíparas bien manejadas pueden mostrar un intervalo de parto a primer celo fértil de 30 a 45 días más prolongado que en las vacas multíparas (Sepúlveda, 2001).

Un factor vital que influye sobre los parámetros reproductivos es la detección de celos que permite inseminar vacas que están realmente aptas para ser servidas (Stevenson et al., 1983; Mc Dougall y Hampson, 1992). La baja eficiencia en la detección de los celos es el factor más simple que afecta cualquier intervalo reproductivo postparto. Hay reportes que indican que cerca del $50 \%$ de los celos pasan desapercibidos por el productor (Butler y Smith, 1989). Stevenson et al. (1983) afirman que con un nivel de 70\% de detección de celo se puede lograr una adecuada eficiencia reproductiva. Se requiere entrenar al personal, asignar más tiempo a la detección de celo y emplear métodos y ayudas adicionales para mejorar la eficiencia de la detección del celo (Sepúlveda, 2001). Muchas de estas tecnologías deberían validarse bajo las condiciones del medio local para comprobar su real contribución al desarrollo y mejoramiento de la ganadería bovina.

\section{Conclusiones}

- La edad al primer servicio (17.5 meses) y la edad al primer parto (27.2 meses) en establos lecheros de la zona implican un tardío inicio de la vida reproductiva.

- Vacas con parto en meses fríos mostraron una mejor eficiencia reproductiva que aquellas que parieron en otros meses del año. Similarmente, las multíparas tuvieron un mejor comportamiento reproductivo que las primíparas.

\section{Literatura Citada}

1. Arana C, Echevarría L, Segura J. 2006. Factores que afectan el intervalo parto-primer servicio y primer servicioconcepción en vacas lecheras del valle del Mantaro durante la época lluviosa. Rev Inv Vet, Perú 17: 108-113.

2. Butler W, Smith R. 1989. Interrelationships between energy balance on postpartum balance reproductive function in dairy cattle. J Dairy Sci 72: 767-777.

3. Echevarría L, Huanca W, Delgado A. 2002. Identificación de las limitantes del comportamiento reproductivo y la eficiencia de la IA en ganado lechero de la zona de Lima. Rev Inv Vet, Perú 13(2): 18-27.

4. Gamarra M. 2001. Situación actual y perspectivas de la ganadería lechera en la cuenca de Lima. Rev Inv Vet, Perú 12(2): 1-13.

5. García M. 2002. User manual for LIMA. Lima: Univ. Peruana Cayetano Heredia. 65 p.

6. García M. 2004. Uso de base de datos en la investigación pecuaria. Mundo Vet, Perú 2(5): 8-18.

7. Inostroza M, Sepúlveda N. 1999. Actividad reproductiva postparto en vacas frisonas. Arch Zoot 48: 429-432.

8. Loeffer SH, De Vries MJ, Schukken YH. 1999. The effect of time of disease occurrence, milk yield, and body condition on fertility of dairy cows. J Dairy Sci 82: 2589-2594.

9. Mc Dougall S, Hampson A. 1992. Efficacy of detection of oestrus in a dairy herd. Austr Vet J 69(4): 96-98.

10. Salazar I. 1992. Parámetros reproductivos y observación de celos en la cuenca lechera de Lima en los años 19901991. Tesis de Bachiller. Lima: Facultad de Medicina Veterinaria, Univ. Nacional Mayor de San Marcos. 47 p.

11. Sepúlveda N. 2001. Limitantes en los programas de inseminación artificial en ganaderías lecheras del sur de Chile. Rev Inv Vet, Perú 12 (Supl 1): 105-110.

12. Silva HM, Wilcox CJ, Thatcher W, Becker RB, Morse D. 1992. Factors affecting days open, gestation length, and calving interval in Florida dairy cattle. $\mathrm{J}$ Dairy Sci 75: 288-293. 
D. Ortiz et al.

13. Stevenson JS, Schmidt MK, Call EP. 1983. Factors affecting reproductive performance of dairy cows first inseminated after five weeks postpartum. J Dairy Sci 66: 1148-1154.
14. Westwood CT, Leant J, Garvin JK. 2002. Factors influencing fertility of Holstein dairy cows: a multivariate description. J Dairy Sci 85: 3225-3237. 